Primljen / Received: 9.4.2012.

Ispravljen / Corrected: 23.6.2012.

Prihvaćen / Accepted: 23.7.2012.

Dostupno online / Available online: 30.7.2012.

\section{Analysis of ground settlement caused by tunnel construction}

Author:

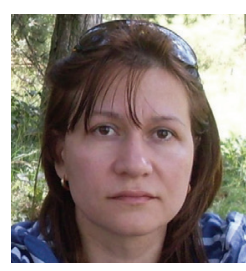

Snežana Maraš-Dragojević, MSc.CE University of Belgrade Faculty of Civil Engineering snezamd@grf.bg.ac.rs

\section{Snežana Maraš-Dragojević}

\section{Analysis of ground settlement caused by tunnel construction}

Prediction of ground settlement is considered as highly significant in the design of tunnels located in urban areas. 2D and 3D modelling of tunnel construction, as needed for settlement analysis, is made according to the finite-element method. The ground settlement profiles, obtained during simulation of the small-depth openface tunnel excavation in clayey-marly terrain, are presented. Settlement cross sections obtained by $2 \mathrm{D}$ and $3 \mathrm{D}$ analyses are compared.

\section{Key words:}

tunnel, ground surface settlement, 3D modelling, finite-element method

Pregledni rad

Snežana Maraš-Dragojević

\section{Analiza slijeganja površine terena uslijed izgradnje tunela}

Važan zadatak pri projektiranju tunela u urbanim područjima jest predvidanje slijeganja površine terena. U radu je za procjenu slijeganja provedeno 2D i 3D modeliranje procesa izgradnje tunela metodom konačnih elemenata. Prikazani su profili slijeganja površine terena dobiveni pri simulaciji izgradnje tunela otvorenim čelom, na maloj dubini, u glinovito-laporastim sredinama. Uspoređeni su poprečni profili slijeganja dobiveni 2D i 3D analizama.

Ključne riječi:

tunel, slijeganje površine terena, 3D modeliranje, metoda konačnih elemenata

Übersichtsarbeit

\section{Snežana Maraš-Dragojević}

\section{Analyse der Setzung der Geländeoberfläche infolge eines Tunnelbaus}

Eine wichtige Aufgabe bei der Tunnelprojektierung in Stadtgebieten ist die Prognosierung der Setzung der Geländeoberfläche. In der Arbeit wurde für die Prognosierung der Setzung eine 2D- und 3D-Modellierung des Prozesses des Tunnelbaus mit der FiniteElement-Methode durchgeführt. Es sind die Setzungsprofile der Geländeoberfläche dargestellt, die durch Simulation eines Tunnelbaus mit einer offenen Front in kleiner Tiefe in Ton- und Mergelgegenden erhalten wurden. Es wurde ein Vergleich von QuerprofilSetzungen, die man durch 2D - und 3D - Analysen erhalten hat, angestellt.

Tunnel, Setzung der Geländeoberfläche, 3D-Modellierung, Finite-Element-Methode 


\section{Introduction}

Speedy development of big cities over the past decades has given rise to numerous demands aimed at achieving greater use of underground space. Tunnels are needed to accommodate transport, electricity, water supply, sewerage and communication systems. Many works currently undertaken in all parts of the world in the field of tunnelling are related to the construction and extension of underground network in big overpopulated cities. It may reasonably be expected that tunnel projects of this type will become increasingly important in the near future (as a response to the pressing need to reduce traffic jams and air pollution). In cities, tunnels are located at low depth under densely populated zones in soil or soft rock, and their construction can have very unfavourable effects on existing facilities and structures. It is therefore highly significant to evaluate in great detail settlement hazards prior to actual tunnel construction. However, this task is everything else but simple. To make adequate assessment of settlement hazard, numerous factors should be taken into account in the calculations: 3D effect of tunnel construction, construction methods and details, tunnel depth and diameter, initial state of stress, and the stress-strain behaviour of soil surrounding the tunnel. Due to high complexity of this issue, many investigations were made, and are still being made, in this field by researchers in all countries of the world.

Methods used for analyzing ground settlement due to tunnel construction can be divided into three groups: empirical methods, analytical solutions, and numerical methods. Empirical methods are characterized by fairly simple calculation procedures, and are extensively used in practice. They provide very good results when tunnelling conditions are well known, i.e. when design parameters are adequately calibrated. Analytical methods provide simple (mostly elastic or elastoplastic) closed-form solutions, but their use is limited to 2D analysis of circular-section tunnels in homogeneous environment, and they can not adequately account for structure and soil interaction effects. On the other hand, numerical methods - such as the finite element method (FEM) - are capable of taking into account: heterogeneity of the environment, non-linear behaviour of soil, complex geometry problems, structure and soil interaction, and construction methods.

Tunnel construction is a three-dimensional process and so the 3D numerical modelling is indispensible to ensure proper analysis of settlement at ground surface, and stressstrain situation in the tunnel structure, and the surrounding soil. Although development of the finite-element method has enabled an efficient three-dimensional analysis, some additional difficulties still occur in practical application, primarily because of substantial increase in the scope of analysis, time requirements, and cost of analysis. As the 3D tunnel construction modelling based on the finite-element method is extremely demanding, the use of numerical methods in engineering practice is still limited to $2 \mathrm{D}$ models. When the tunnel construction process is evaluated using the $2 \mathrm{D}$ analysis, it is indispensible to introduce certain assumptions that take into account 3D effects of tunnel construction, namely the stress-strain changes that occur at the tunnel face. 3D and $2 \mathrm{D}$ tunnel construction modelling procedures based on the finite-element method will be presented in this paper after a brief introductory presentation of empirical methods. Results obtained by $3 \mathrm{D}$ and $2 \mathrm{D}$ analysis of terrain settlement due to open-face tunnel construction in clayey-marly soil in the zone of Belgrade, are also presented.

\section{Use of empirical method in settlement analysis}

The transverse profile of settlement can fairly well be described for many tunnels based on ground surface settlement measurements, using the Gaussian function of normal distribution [1]. Although the use of this curve has no theoretical justification, it has been widely accepted in practice, and is recognized as an empirical method that is nowadays extensively used in the evaluation of ground surface settlement. Vertical settlements in transverse direction are defined by the following expression:

$S_{v}(x)=S_{v \max } \exp \left(-\frac{x^{2}}{2 i^{2}}\right)$

where $S_{v \max }$ is the maximum settlement occurring above the tunnel axis, $x$ is the horizontal distance from the tunnel axis, and $i$ is an important parameter defining the cross-sectional width of settlement, and presenting the horizontal distance from the tunnel axis to the profile inflexion point, as shown in Figure 1.

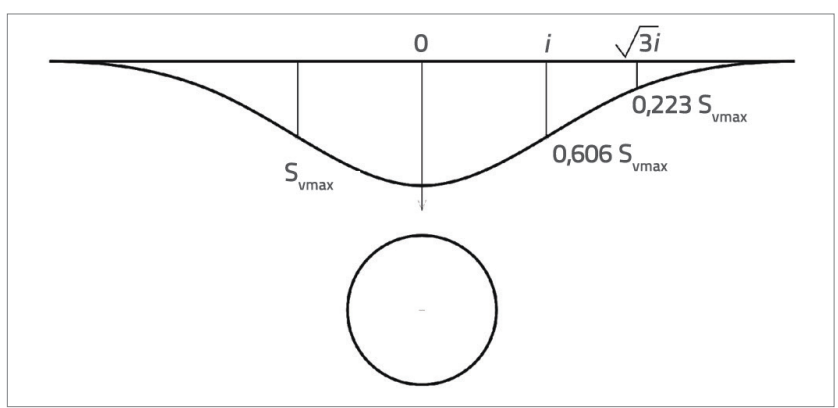

Figure 1 Profile (Gaussian curve) of ground settlement due to tunnel construction

The settlement of soil due to tunnel construction is normally characterized by the parameter known as the volume loss or ground loss. This is the relationship between the soil volume deformed into the tunnel opening, and the theoretical volume of tunnel excavation. In tunnels excavated in clayey soil, the settlements registered during tunnelling work usually occur in undrained conditions (without change in volume), and so it can be concluded that the loss of soil volume at the contour of excavation is equal to the ground surface settlement volume obtained by integration of the expression 1 : 
$V_{s}=\sqrt{2 \pi} \cdot i \cdot S_{v \max }=2,5 \cdot i \cdot S_{v \max }$

For the tunnel excavation diameter $D_{1}$, the volume loss influence factor $V_{L}$ (expressed as percentage) amounts to:

$V_{L}=\frac{V_{S}}{\frac{\pi D^{2}}{4}} \cdot 100 \%$

If expressions (2) and (3) are combined, the expression for maximum settlement of ground surface can be obtained using the parameter $V_{\text {: }}$

$S_{v \max }=0,313 \cdot V_{L} \cdot \frac{D^{2}}{i}$

The parameter $V_{L}$ is dependant on the tunnel construction method and the type of soil. Significant advancements have been made over the past decades in tunnel construction technology. In addition to traditional construction methods, such as the New Austrian Tunnelling Method (NATM), an extensive use is also made of the tunnelling shield, which enables tunnelling under highly complex geotechnical conditions in soft soil with small thickness of overburden. The experience in the use of tunnelling techniques and knowledge of geotechnical conditions, i.e. settlement information from already completed tunnels, is highly valuable in the evaluation of the $V_{L}$ parameter. An extensive data base on ground surface settlement was generated during tunnel construction activities in London. Realistic $V_{L}$ values for homogeneous soil range from 0.5 to 2 percent, depending on the equipment and experience of the tunnel excavation crew. The $V_{L}$ value of 1.4 percent was obtained by settlement measurements for the Jubilee Line under the Green Park in London. This value corresponds well to the typical range of one to two percent for shield excavation of open-face tunnels in London clay, as indicated in [2]. However, greater values of $3.3 \%$ and $2.9 \%$ (for the west and east tunnel tubes, respectively) were registered during construction of the open-face tunnel under the St. James Park in London (Jubilee Line Extension) [3]. According to $[4,5]$, typical $V$, values for the open-face tunnel construction in soft soil generally range from 1 to 3 percent, while much lower values are obtained in closed-cut tunnelling using modern machinery, such as the EPB shield. Measurement data from the CTRL project (Channel Tunnel Rail Link) for tunnels in London reveal that very low $V$, values ranging from 0.25 to 0.5 percent can be obtained by careful operation of the EPB shield [6]. The importance of $V_{L}$ value for settlements due to tunnel excavation is further emphasized by the fact that limit values of this parameter are often specified in contract documents for tunnel construction [7].

The width of settlement trough is defined by parameter $i$ which represents, as already indicated, horizontal distance between the settlement profile inflection point and the tunnel axis (Figure 1). A linear relationship is proposed according to
[8] based on ground surface settlement measurements made for tunnels in clay:

$i=0,43 z_{0}+1,1$

where $i$ and $z_{0}$ are expressed in meters.

The expression is simplified for most practical applications, as follows:

$i=K \cdot z_{0}$

In this respect, the value of $\mathrm{K}=0.5$ can be adopted for clayey soil. According to [9], the value of $K=0.5$ was obtained based on ground surface settlement measurements made on a large number of tunnels. Based on a large quantity of information from tunnelling projects in clayey and sandy soil, some authors obtained $K$ values ranging from 0.4 to 0.6 , with an average of $K$ $=0.5$, for clayey soil, and values ranging from 0.25 to 0.45 , with an average of 0.35 , for sandy soil [4].

Empirical methods are quite simple and are often used in practice, especially in early stages of tunnel design. They are to a lesser or greater extent combined with analytical methods and calculations using the finite element method, and parameters are calibrated based on data gathered from previously built tunnels. Empirical methods provide very good results when tunnel construction conditions are well known, i.e. when design parameters are adequately calibrated.

\section{Numerical modelling of tunnel construction}

Despite the fact that empirical and analytical methods are both simple and useful, the possibilities for their use are quite limited. Although the stress-strain state in soil and tunnel structure, and ground surface settlements, are dependent on geotechnical properties of soil, tunnel geometry, and tunnel depth, it can rightfully be stated that they are to the greatest extent dependent on the tunnel construction procedure. This is why the tunnel construction process must adequately be simulated in the analyses. This can not be achieved by analytical methods, and so numerical methods must be applied. The finite-element method enables development of a design model that can be used to conduct the stress-strain analysis by construction stages, taking at that into account relevant geotechnical properties of soil.

\subsection{D modelling by finite-element method}

A three-dimensional stress-deformation state develops at the face during the tunnelling work. In the course of tunnel construction, the load is transferred via the rock mass in front of the face, from the sides of the cross section, and also via the already formed lining. The lining takes on load in the transverse and longitudinal directions of the tunnel and, in addition, the lining is placed on the already deformed 
excavation surface. The study of this partial relaxation, or deformation, of the excavated surface at the tunnel face, which occurs prior to installation of lining, is of crucial significance for an adequate analysis of stress-strain states in the tunnel structure, and in the surrounding environment. To enable this study, we have to make use of the three-dimensional analysis which simulates the progress of works, stress changes, and deformations in the vicinity of the tunnel face.

The process of tunnel construction is usually simulated using the so called "step-by-step" procedure [10-12]. The first step is the analysis of the initial or in-situ state of stress in soil which is followed by simulation, step-by-step, of excavation and support work sequences. The simulation of tunnelling work has to be made on the tunnel length that is sufficient to obtain a steady state behind the tunnel face. This procedure is applied for simulating construction of open-face tunnels. When closed-cut tunnelling with shield is simulated, the modelling can include some construction details such as the support pressure at the tunnel face, grouting pressure, etc. Thanks to considerable advancements that have in recent years been made in information technology, an increasing number of papers presenting 3D modelling of tunnel excavation can be found in literature. Most authors use the step-by-step procedure to simulate construction of open-face tunnels using traditional methods (NATM) and open-faced shield. Katzenbach and Breth [10] analyzed construction of a NATM tunnel in Frankfurt marly clay using the 3D modelling with the finite-element method and, at that, the nonlinear elastic stress and strain relationships are assumed. By comparing the measured and calculated terrain surface settlements, they came to conclusion that the computation procedure used provides satisfactory results. Other authors analyze a NATM tunnel in rock mass [11] using the step-bystep method and a rheological model in order to explain the time-dependent interaction between the shotcrete lining and the surrounding environment. Some authors proposed the procedure in which a "small" computation section, moving during simulation of each tunnelling sequence, is adopted [12] (the condition for adoption of this procedure is that the rock mass must be homogeneous, and that there is no change in tunnel cross section, overburden height and in-situ stress in longitudinal direction). Some authors $[13,14]$ presented results of the elastic $3 D$ analysis based on the finite-element method for tunnels in rock using the step-by-step procedure, with displacement of computation section. However, some authors modelled construction of a NATM tunnel in London clay using 2D and 3D models (nonlinear behaviour of London clay was modelled using the SDMCC model (Strain Dependent Modified Cam Clay)) [15]. The transverseprofile of settlement obtained by calculations was wider and shallower when compared to the profile obtained by in-situ measurements. This corresponds well with conclusions reached by other authors who claim that the ground surface settlement analysis, based on the finite-element method, results in excessively wide and shallow settlement transverse in overconsolidated soil, with high values of lateral pressure coefficient $K_{0}$. Results of $2 \mathrm{D}$ analysis based on the finite-element method (i.e. the volume loss method) for a tunnel in London clay with $k_{0}=1.5$, with the use of linear elastic and nonlinear elastic models in combination with the Mohr-Coulomb failure criterion, are presented in great detail in [16]. The transverse profiles of settlement obtained were excessively wide and shallow when parameters realistic for London clay were adopted and, despite expectations, the soil anisotropy modelling did not improve the results considerably. Detailed 3D analyses of settlement due to open-face tunnel construction in London clay using the linear elastic-perfectly plastic soil model, in which the anisotropy levels and $K_{0}$ values were varied, were also conducted $[17,18]$. 3D analyses based on the finite-element method were also made for the NATM using the step-by-step procedure and the linear elastic perfectly plastic model, with the Mohr-Coulomb failure criterion and $K_{0}=0.66$, [19]. An identical shape of settlement profile was obtained by comparison of $3 \mathrm{D}$ and $2 \mathrm{D}$ analyses and, at that, the same settlement value was obtained when the corresponding soil relaxation level before installation of lining (I method) was adopted in the 2D analysis. Some authors [20] conducted the 3D modelling based on the finite-element method for tunnel construction in soil, with the Mohr-Coulomb elastoplastic constitutive relationship and, at that, the effects of strengthening (soil nailing) at tunnel face were analyzed with respect to stresses in lining and soil displacement.

2D and 3D analyses of tunnels in London clay [21] were conducted in order to estimate the influence of 3D modelling, soil anisotropy, and lateral pressure coefficient $\mathrm{K}_{0^{\prime}}$ on the ground surface settlement due to tunnel construction. Analyses with nonlinear elastoplastic isotropic soil model (small strain stiffness model according to [22] and MohrCoulomb failure criterion), and the lateral pressure coefficient $K_{0}=1.5$, have shown that the shape of the transverseprofile of settlement was not significantly influenced by $3 D$ modelling, and that this profile remained excessively wide when compared to measurement results (even use of soil anisotropy, with parameters relevant for London clay, did not greatly improve the results). The $3 \mathrm{D}$ analysis of ground surface settlement was also conducted for the SCL (Sprayed Concrete Lining) tunnel construction in London clay, using the nonlinear small strain BRICK soil model [24] which takes into account the anisotropic behaviour [23]. A good correspondence with the Gaussian settlement curve (which proved good for approximation of measurement results) was obtained, and it was concluded that $3 \mathrm{D}$ modelling techniques are an efficient tool for the estimation of ground surface settlement due to tunnel construction. The level of accuracy in the estimation of displacement due to NATM tunnel construction in stiff clay with a high value of $\mathrm{K}_{0}$, was 
analyzed at the Heathrow express trial tunnel in London [25], using the 3D analysis based on the finite-element method. London clay behaviour was modelled by means of two models: hypoplastic model for clay, proposed according to [25], and the modified Cam-clay model (MCC). It was concluded that the hypoplastic model predicts settlement better than the MCC model, with the settlement profile somewhat wider than the profile obtained by measurements. The hypoplastic model for predicting displacements during NATM tunnel construction in stiff clay was also used for the Kralovo Pole Tunnel in Brno (Czech Republic) [26]. It was concluded that the model predicts well settlements and horizontal displacements on the ground surface, and vertical displacements along the depth, while horizontal settlements in the vicinity of the tunnel are overestimated.

\section{2. $2 \mathrm{D}$ modelling using the finite element method}

As the 3D numerical modelling of tunnel construction is extremely demanding from the standpoint of capacity and time of computer operation, the use of numerical method is nowadays still limited to $2 \mathrm{D}$ models. When the tunnel construction process is considered using the $2 \mathrm{D}$ analysis (plane strain), then some assumptions must be adopted to take into account the partial relaxation of stress at the tunnel face, i.e. deformations that occur at the tunnel face before installation of lining. Several methods have so far been proposed in literature for the simulation of tunnel construction using $2 \mathrm{D}$ models: stress reduction method (convergence-confinement or I - method) [27], progressive softening method [28], $V_{L}$ (volume loss) control method [16], and the Gap method [29-30]. The method most often used for the $2 \mathrm{D}$ modelling of tunnel construction is the stress reduction method (I-method) in which the partial relaxation of stress, which occurs at the tunnel face, is introduced in the $2 \mathrm{D}$ model via the I parameter which represents the percentage of initial stress relaxation before installation of tunnel lining (lining takes on the load $(1-I) \times s_{0}$, where $s_{0}$ is the initial stress in soil). The factor of relaxation, l, is dependent of the tunnel geometry, initial stress, soil properties, and the length of the unsupported section at the tunnel face. Greater values of this parameter correspond to greater lengths of the unsupported section at the tunnel face when soil deformations are greater and stresses in lining are smaller while, conversely, smaller I values represent smaller deformations and greater forces in the lining. Therefore the value of I parameter must be defined in this method. In fact, it has been shown that the method gives good results when an adequate value of this parameter is adopted.

The 3D modelling of tunnel construction by the finite element method using the step-by-step procedure, and the $2 \mathrm{D}$ modelling according to the finite-element-method using the stress reduction method, are conducted in this paper.

\subsection{Details about numerical analysis of settlement}

The ground surface settlement analysis was conducted for an open-face tunnel of circular section, situated in clayeymarly formations typical for the centre of Belgrade [31]. The computations were conducted using the software DIANA Finite Element Analysis (TNO DIANA BV). This program can be used to conduct three-dimensional nonlinear analyses, and to model individual phases of construction.

The terrain cross-section adopted consists of loess (Aeolian deposit of yellowish colour) $5 \mathrm{~m}$ in thickness, which lies on the degraded, yellow-gray marly clay $15 \mathrm{~m}$ in thickness, which in turn rests on a gray unaltered marly clay and marl. Calculations were made for the tunnel of circular cross section, $6 \mathrm{~m}$ in diameter, with the concrete lining $0.35 \mathrm{~m}$ in thickness (in accordance with the Technical and economic feasibility study for rapid public urban transport in Belgrade, Phase 3: Conceptual design for the first stage of metro, 1981). The tunnel axis is at the depth of $z_{0}=15 \mathrm{~m}$, in yellow-gray degraded marly clay.

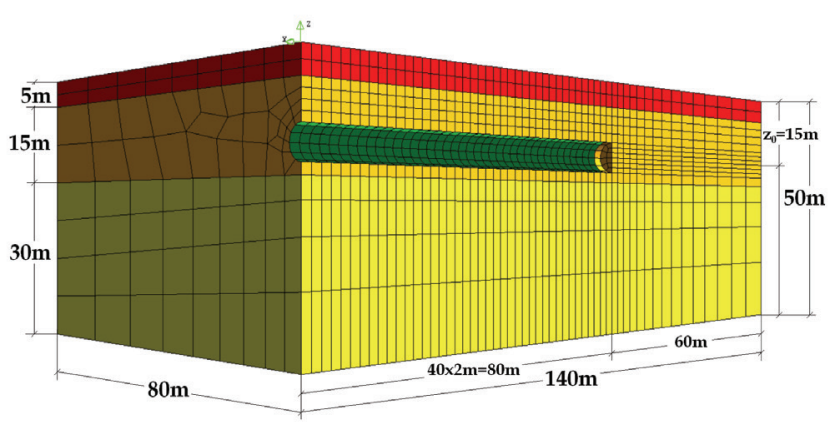

Figure 2. 3D finite-element design model ( $40^{\text {th }}$ step of the analysis)

The 3D finite-element model adopted in the analysis is shown in figure 2 . The design cross-section adopted measures 80 $\times 50 \times 140 \mathrm{~m}$, and is composed of the total of 26085 nodes and 5734 elements. As the nonlinear analysis of soil had been made, the analysis was conducted using elements of "higher order" which have nodes in centre, in addition to nodes at corners. The soil was modelled using a twenty-node element, i.e. the isoparametric brick element, while lining was modelled using the quadrilateral isoparametric curved shell element with 8 nodes [32]. The symmetry of problem, as related to the $\mathrm{z}$ axis, was taken into account during establishment of the finite-element mesh. The finite-element mesh was first formed in the $x-z$ plane, and was then extended in the longitudinal direction. The tunnel excavation was simulated in the negative $y$-direction, in the length of $80 \mathrm{~m}$, starting from $y$ $=0$, and in forty steps. The length of excavation (unsupported section at the face) was $d=2 \mathrm{~m}$. The length of the adopted design profile in longitudinal direction is $140 \mathrm{~m}$. This profile is formed of forty sections, each $2 \mathrm{~m}$ in length, and the remaining $60 \mathrm{~m}$ is the adopted distance from the tunnel face in the last step of the analysis to the mesh limit. The mesh 
configuration is the same for all node planes perpendicular to the tunnel axis. The case of excavation with vertical face was considered, i.e. it was assumed that the excavation will be made in full cross-section. Boundary conditions were set to prevent displacement in the direction perpendicular to the corresponding boundary and to prevent displacement in all directions at the bottom boundary of the mesh. An additional condition was set to prevent rotation around the longitudinal axis in the lining nodes in symmetry plane.

The finite-element model is characterized by such structure that enables analysis in all phases of tunnel construction. Initial sequences of tunnel construction simulation process are shown in Figure 3:

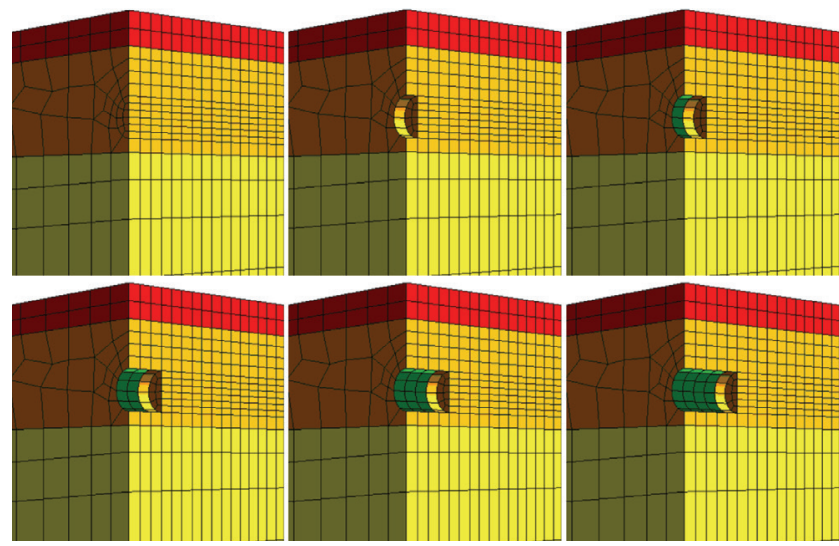

Figure 3. Sequences of 3D simulation of tunnel construction process

The tunnelling work simulation was conducted using the stepby-step procedure. The first step is the analysis of the initial or in-situ state of stress in soil. This is followed by simulation of excavation and support work sequences in separate design steps, starting from the portal. The excavation is simulated by deactivating elements within the tunnel contour at the tunnel face, in the excavation length, $d$, which causes movement at the excavation contour. In the next phase, lining elements are activated at the excavation contour deformed as mentioned above, and the excavation of the next section is simulated. The length within which the tunnel construction is simulated must be sufficient to enable formation of the steady-state of settlement, i.e. of a horizontal part of the longitudinal profile of settlement, and this at an appropriate distance behind the tunnel face. In this paper, the tunnel construction is simulated in forty steps with the progress of $d=2 \mathrm{~m}$, which means that the tunnel face is $80 \mathrm{~m}$ away from the portal in the last step of the calculation.

$2 \mathrm{D}$ analyses were conducted using the stress reduction method (I method), and the plane state of strain was assumed. The configuration of the $2 \mathrm{D}$ model mesh is the same as that of the $3 \mathrm{D}$ model mesh, in the plane perpendicular to the tunnel axis. The soil was modelled with the rectangular isoparametric plane strain element with eight nodes, and the lining was modelled using the curved infinite shell element with three nodes [32]. The analysis was conducted in three steps. Just like in $3 \mathrm{D}$ analysis, the analysis of the initial state of stress in soil was conducted in the first step. Elements within the excavation contour were removed in the second step, and the load $\lambda \times \sigma_{0}$ was applied, where $\sigma_{0}$ is the initial stress in soil. This step of the analysis resulted in movement of the excavation boundary and in partial relaxation of initial stress. In the third step, lining elements were installed on the excavation contour deformed in this way, and the total initial stress in soil was applied.

In this paper, the analyses were made with the assumption of elastoplastic behaviour of material, and the Mohr-Coulomb failure criterion was applied. Due to engineering-geological and hydrogeological characteristics of the terrain, the situation without ground water was taken into account. The MC model soil parameters are presented in Table 1. The dilatation was neglected by assuming that the angle of dilatation of all layers is equal to zero.

The concrete lining $0.35 \mathrm{~m}$ in thickness was modelled by assuming linear elastic behaviour of concrete, with the following parameters: $\rho=2,5 \mathrm{~g} / \mathrm{cm}^{3}, E=15 \mathrm{GPa}$ i $v=0,15$.

\subsection{Overview and comparison of settlement results obtained by $3 \mathrm{D}$ and $2 \mathrm{D}$ modelling}

Longitudinal settlement profiles obtained in individual steps of the 3D analysis are presented in Figure 4. As can be seen in this Figure, the steady state of displacement (horizontal part of the longitudinal profile) was obtained at approximately $30 \mathrm{~m}$ behind the tunnel face, during simulation of tunnel excavation $80 \mathrm{~m}$ in length (40 steps, each $2 \mathrm{~m}$ in length). At that, disturbances related to boundary conditions at the left side of the model occur at the initial part of the profile [19].

Table 1. MC model soil parameters

\begin{tabular}{|c|c|c|c|c|c|c|}
\hline Layers & $\begin{array}{c}\rho \\
{\left[\mathrm{g} / \mathrm{cm}^{3}\right]}\end{array}$ & $\begin{array}{c}E \\
{[\mathrm{MPa}]}\end{array}$ & $v$ & $\begin{array}{c}\mathrm{c}^{\prime} \\
{[\mathrm{kPa}]}\end{array}$ & $\begin{array}{c}\phi^{\prime} \\
{\left[{ }^{\circ}\right]}\end{array}$ & $\mathrm{K}_{\mathrm{o}}$ \\
\hline First layer (Loess) & 1,85 & 10 & 0,4 & 18 & 23 & 0,65 \\
\hline Second layer (degraded marly clay) & 2,0 & 15 & 0,3 & 20 & 20 & 0,85 \\
\hline Third layer (grey unaltered marly clay and marl) & 2,0 & 60 & 0,3 & 60 & 25 & 0,58 \\
\hline
\end{tabular}




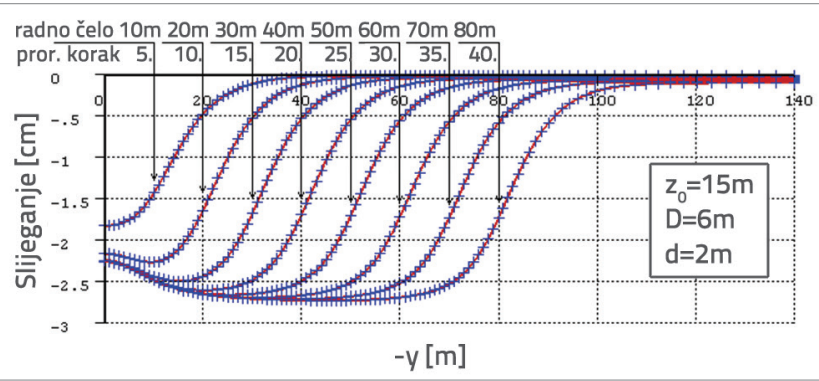

Figure 4. Development of longitudinal settlement profiles with the progress of tunnelling work

Figure 5 shows ground surface settlement troughsobtained in the fortieth step of the analysis, during simulation of tunnel construction in the length of $40 \times 2 \mathrm{~m}=80$, for vertical cross section at the tunnel face: $y=-80 m$ and $y=-78 m$, and for the cross section $y=-50 \mathrm{~m}$ (steady-state displacements).

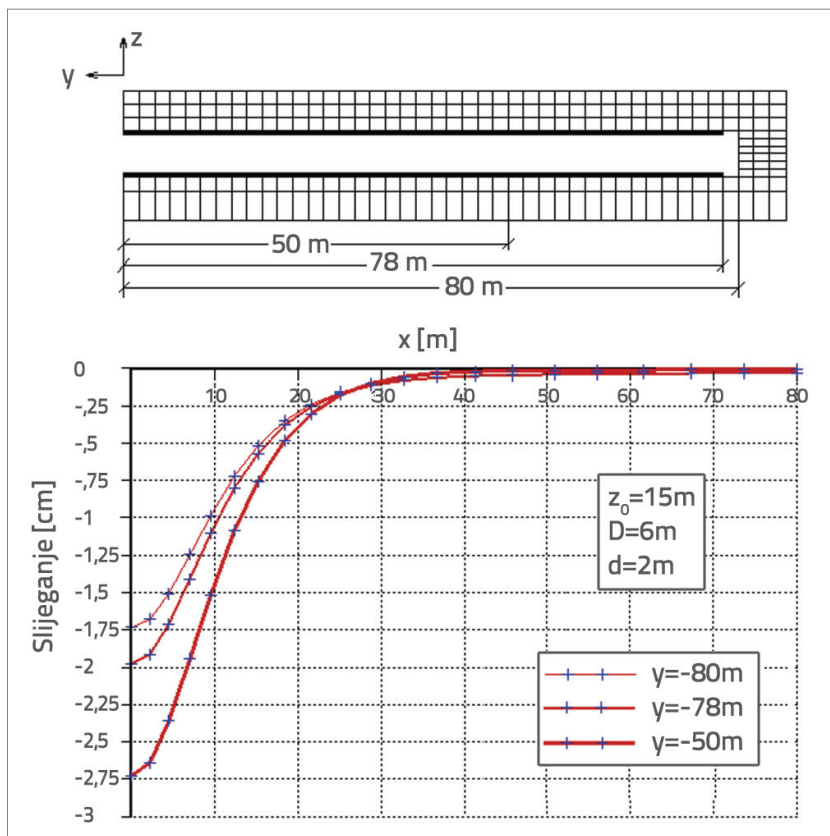

Figure 5. Cross sectional profiles of settlement obtained by 3D analysis during simulation of tunnelling work

Figure 6 shows comparison of settlement profiles obtained by $3 \mathrm{D}$ analysis during simulation of tunnel construction in the length of $40 \times 2 m=80 m$ (for the cross section $y=-50$ $\mathrm{m}$ steady-state displacements), with profile obtained by $2 \mathrm{D}$ analysis using the stress reduction method, with $\lambda=0.63$. The stress reduction factor $\lambda$ was defined based on steady-state settlement values which were obtained by $3 \mathrm{D}$ analysis. To enable comparison, the figure also shows empirical Gaussian curves for $i=0,5 z_{0}$ and $i=0,6 z_{0}$. As can be seen in the figure, $3 \mathrm{D}$ and $2 \mathrm{D}$ analyses give similar settlement profiles when an appropriate stress reduction coefficient is adopted. It can also be seen that settlement profiles obtained by calculations using the finite-element methods are somewhat wider than the empirical Gaussian curve.

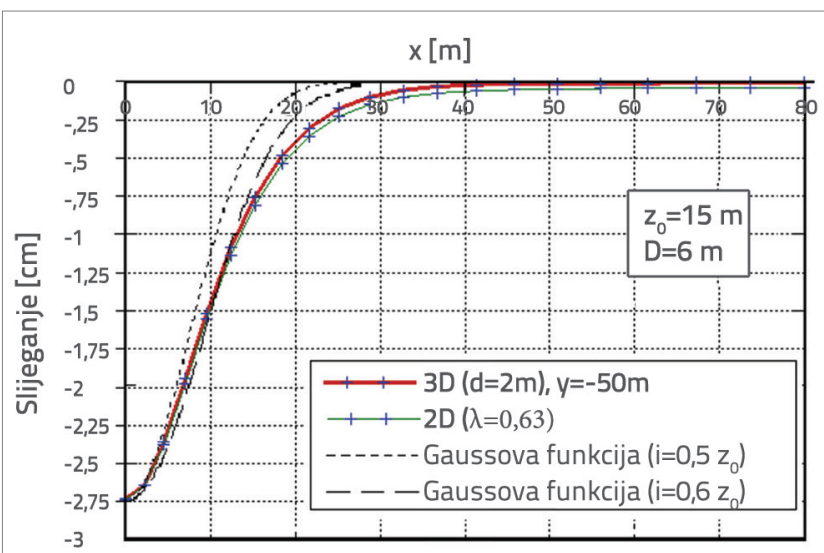

Figure 6. Comparison of transverse settlement profile obtained by 3D analysis with the profile obtained by $2 \mathrm{D}$ analysis based on the stress reduction method

Contours of vertical displacement in the cross section of $y=$ $-50 \mathrm{~m}$ (steady-state) are given in Figure 7. in order to explain the displacement across depth.

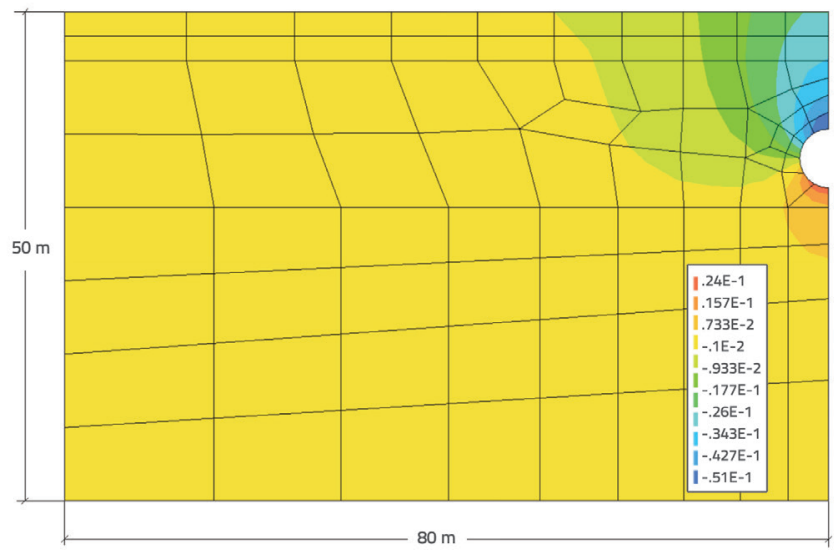

Figure 7. Contours of vertical displacement in cross section $y=-50 \mathrm{~m}$

\section{Conclusion}

It is very important to adequately predict and control ground surface settlements during the design and construction of tunnels in urban areas. Empirical methods for estimation of ground surface settlement due to tunnel construction are relatively simple procedures that are very often used in practice. They provide very good results when tunnelling conditions are well known, i.e. when design parameters are adequately calibrated. The experience in the use of tunnelling techniques and knowledge of geotechnical conditions, i.e. settlement information from already completed tunnels, is highly valuable in the evaluation of the $V_{L}$ parameter. Empirical method are to a lesser or greater extent combined 
with analytical methods and calculations using the finite element method, and parameters are calibrated based on data gathered from previously built tunnels.

Numerical methods - such as the finite-element method take into account complex geometry, stress-strain behaviour of soil, and tunnel construction procedures. A threedimensional analysis which simulates the progress of works, stress changes, and deformations in the vicinity of the tunnel face, is needed for an adequate analysis of the stress-strain state in the tunnel structure and the surrounding zone.

The 3D modelling of the open-face tunnel construction, using the step-by-step procedure, was conducted in the paper. At that, the tunnel construction was simulated in the length of $80 \mathrm{~m}$, in 40 computational steps, with the progress of $\mathrm{d}=2 \mathrm{~m}$. The length within which the tunnel construction is simulated must be sufficient to enable formation of the steady-state of settlement, i.e. of a horizontal part of the longitudinal profile of settlement, at an appropriate distance behind the tunnel face. The steady state of displacement was obtained at approximately $30 \mathrm{~m}(5 \mathrm{xD})$ behind the tunnel face. In 3D analyses, the percentage of stress relaxation in soil at the tunnel face, before the lining is placed, is obtained directly and is dependent of the tunnel geometry, characteristics of the soil, and the length of the unsupported section at the tunnel face. In 2D analyses, in order to take into account partial relaxation of stress at the tunnel face, or deformations that have occurred at the tunnel face before installation of lining, it is necessary to make at least one assumption, e.g. the volume loss parameter, $V_{L^{\prime}}$ or the percentage of stress relaxation before installation of lining, i.e. the stress reduction factor, $\lambda$, or, alternately, the real displacement at the contour can be set. $2 \mathrm{D}$ analyses were conducted in the paper using the stress reduction method ( $\lambda$ method). In this method, the $\lambda$ parameter can be assumed based on engineering assessment, or according to experience gained on similar projects, or by comparing results obtained by $3 \mathrm{D}$ and $2 \mathrm{D}$ analyses. Based on calculation results obtained in this paper, it can be concluded that $3 \mathrm{D}$ and $2 \mathrm{D}$ analyses provide similar profiles of settlement, provided that an appropriate stress reduction coefficient is adopted.

\section{REFERENCES}

[1] Peck, R.B.: Deep excavations and tunnelling in soft ground. In Proceedings of the 7th International Conference on Soil Mechanicsand Foundation Engineering, Mexico, State of the art volume: 225-290, 1969.

[2] Attewell, P.B. \& Farmer, I.W.: Ground deformations resulting from tunnelling in London Clay. Can. Geotech. J. 11(3): 380-395, 1974.

[3] Standing, J.R., Nyren, R.J., Burland, J.B. \& Longworth, T.I.: The measurement of ground movement due to tunneling at two control sites along the Jubilee Line Extension, Proc. of the International Symposium on Geotechnical Aspects of Underground Construction in Soft Ground, Balkema, Rotterdam, 751-756, 1996.

[4] Mair, R.J. \& Taylor, R.N.: Bored tunneling in urban environment. Proc. $14^{\text {th }}$ International Conference on Soil Mechanics and Foundation Engineering, Hamburg, Balkema, Rotterdam, 23532385, 1997.

[5] Mair, R.J.: Tunnelling and geotechnics: new horizons. Géotechnique 58(9): 695-736, 2008.

[6] ITA-AITES WG "Research": ITA/AITES Report 2006 on Settlements induced by tunneling in Soft Ground. Tunnelling and Underground Space Technology, 22: 119-149, 2007.

[7] Burland, J.B., Standing, J.R. \& Jardine, F.M.: Assessing the risk of building damage due to tunnelling - lessons from Jubilee Line Extension, London. Geotechnical Engineering. Meeting society's need, Vol.1, Swets and Zeitlinger, Lisse, 17-44, 2001.

[8] O'Reilly, M.P. \& New, B.M.: Settlements above tunnels in the United Kingdom - their magnitude and prediction. Tunnelling 82. The Institution of Mining and Metallurgy, London, 173-181, 1982.
[9] Rankin, W.J.: Ground movements resulting from urban tunnelling: predictions and effects. Proc. Conf. Engineering geology of underground movements, The Geological Society, London, 79-92, 1988.

[10] Katzenbach, R. \& Breth, H.: Nonlinear 3-D Analysis for NATM in Frankfurt Clay. Proc. 10th ICSMFE, Stockholm, 315-318, 1981

[11] Swoboda, G., Mertz, W. \& Schmid, A.: Three-dimensional numerical models to simulate tunnel excavation. Proc. 3rd Int. Conf. on Numerical Models in Geomechanics, Niagara Falls, 536$548,1989$.

[12] Wittke, W.: Rock Mechanics: Theory and Applications with Case Histories. Springer-Verlag, Berlin, 1990.

[13] Kielbassa, S. \& Duddeck, H.: Stress-Strain Fields at the Tunneling Face - Three-dimensional Analysis for Two-dimensional Technical Approach. Rock Mechanics and Rock Engineering, 24, 115-132, 1991.

[14] Maraš, S.: Analiza interakcije horizontalne tunelske konstrukcije i stenske mase, Magistarski rad, Univerzitet u Beogradu, Gradevinski fakultet, Beograd, 1997.

[15] Desari, G.R., Rawlings, C.G. \& Bolton, M.D.: Numerical Modelling of NATM Tunnel Construction in London Clay. Geotechnical Aspects of Underground Construction in Soft Ground, Maire\&Taylor (eds), Balkema, Rotterdam, 1996.

[16] Addenbrooke, T.I., Potts, D.M. \& Puzrin, A.M.: The influence of pre-failure soil stiffness on the numerical analysis of tunnel construction. Géotechnique, 47(3), 693-712, 1997.

[17] Lee, G.T.K. \& Ng, C.W.W.: Three-dimensional analysis of ground settlements due to tunnelling: Role of $\mathrm{KO}$ and stiffness anisotropy. Proc. of the International Symposium on Geotechnical Aspects of Underground Construction in Soft Ground, Lyon, 617- 622, 2002. 
[18] Ng, C.W.W. \& Lee, G.T.K.: Three-dimensional ground settlements and stress-transfer mechanisms due to open-face tunnelling. Canadian Geotechnical Journal, 42, 1015-1029, 2005.

[19] Vermeer, P. A., Bonnier, P. G. \& Möller, S. C.: On a smart use of 3D-FEM in tunnelling. Proc. of the 8th Int. Symp. on Numerical Models in Geomechanics - NUMOG VIII, Rome, Balkema, Roterdam, 361-366, 2002.

[20] Galli, G., Grimaldi, A. \& Leonardi, A.: Three-dimensional modelling of tunnel excavation and lining. Computers and Geotechnics, 31, 171-183, 2004.

[21] Franzius, J.N., Potts, D.M. \& Burland, J.B.: The influence of soil anisotropy and $\mathrm{K}_{0}$ on ground surface movements resulting from tunnel excavation. Géotechnique, 55(3): 189-199, 2005.

[22] Jardine, R.J., Potts, D.M., Fourie, A.B. \& Burland J.B.: Studies of the Influence of the Nonlinear Stress-strain Characteristics in Soil-Structure Interaction. Géotechnique 36(3), 377-396, 1986.

[23] Yazdchi, M., Macklin, S.R. \& Yeow, H.C.: 3D modelling of sprayedconcrete-lined tunnels in clay. Proceedings of the Institution of Civil Engineers, Geotechnical Engineering, 159, Issue GE4, 243250, 2006.

[24] Simpson, B.: Retaining structures: displacement and design. Géotechnique, 42(4), 541-576, 1992.

[25] Mašin, D.: 3D Modeling of an NATM Tunnel in High $\mathrm{K}_{0}$ Clay Using Two Different Constitutive Models. Journal of Geotechnical \& Geoenvironmental Engineering 0 ASCE, September 2009, 13251335, 2009.
[26] Svoboda, T., Mašin, D., Boháč, J.: Class A predictions of a NATM tunnel in stiff clay. Computers and Geotechnics, 37, 817-825, 2010.

[27] Panet, M., Guenot, A.: Analysis of convergence behind the face of a tunnel. Tunnelling 82. The Institution of Mining and Metallurgy, London, 197-204, 1982.

[28] Swoboda, G.: Finite element analysis of the New Austrian Tunnelling Method (NATM). In Proc. 3rd Int. Conf. Num. Meth. Geomech, Aachen, Vol. 2: 581-586, 1979.

[29] Rowe, R.K., Lo, K.Y. \& Kack, G.J.: A method of estimating surface settlement above tunnel constructed in soft ground. Canadian Geotechnical Journal, 20: 11-22, 1983.

[30] Lee, K.M. \& Rowe, R.K.: An analysis of three-dimensional ground movements: the Thunder Bay tunnel. Canadian Geotechnical Journal, 28: 25-41, 1991.

[31] Maraš-Dragojević, S. \& Radić, Z.: Some geotechnical aspects of the future Belgrade metro construction. Proc. Under City Colloquium on Using Underground Space in Urban Areas in South-East Europe April 12-14, Dubrovnik, Croatia, 2012.

[32] DIANA Finite Element Analysis, User's Manual release 9.4.3, TNO DIANA BV, Delft, 2010. 